\section{Use of continuous positive airway pressure in the management of community acquired pneumonia}

\author{
A Brett, D G Sinclair
}

\begin{abstract}
Three cases of severe community acquired pneumonia requiring ventilatory support are presented. Continuous positive airway pressure (CPAP) applied via a tightly fitting face mask was used and was successful in two cases; the third required intermittent positive pressure ventilation. More extensive use of CPAP in these circumstances should be considered.
\end{abstract}

(Thorax 1993;48:1280-1281)

Reprint requests to:

Dr D G Sinclair

Received 10 November 1992

Returned to authors

6 January 1993

Revised version received

12 January 1993

Accepted 28 January 1993

Community acquired pneumonia remains a common cause of morbidity and mortality in this country with an estimated incidence of

Table 1 Relevant parameters on admission to hospital

\begin{tabular}{llll}
\hline Parameter & Case 1 & Case 2 & Case 3 \\
\hline White cell count $\left(\times 10^{\circ} / \mathrm{l}\right)$ & $5 \cdot 76$ & $25 \cdot 60^{\star}$ & $12 \cdot 23$ \\
Urea (mmol/l) & $3 \cdot 2$ & $4 \cdot 8$ & $21 \cdot 6^{\star}$ \\
Albumin $(\mathrm{g} / \mathrm{l})$ & 36 & $34^{\star}$ & $32^{\star}$ \\
Diastolic blood pressure $(\mathrm{mm} \mathrm{Hg})$ & 90 & 80 & 80 \\
Respiratory rate (breaths/min) & 26 & $40^{\star}$ & 24 \\
Conscious level & Normal & Normal & Normal \\
\hline
\end{tabular}

^Abnormalities associated with increased mortality. ${ }^{2}$

Table 2 Clinical parameters, arterial oxygen $\left(\mathrm{PaO}_{2}\right)$ and carbon dioxide $\left(\mathrm{PaCO}_{2}\right)$ tensions for each case before and 30 minutes after introduction of CPAP

\begin{tabular}{|c|c|c|c|}
\hline & Case 1 & Case 2 & Case 3 \\
\hline \multicolumn{4}{|l|}{ On admission breathing air: } \\
\hline Pulse rate (beats/min) & 130 & 140 & 120 \\
\hline Respiratory rate (breaths/min) & 26 & 40 & 24 \\
\hline $\mathrm{PaO}_{2}(\mathrm{kPa})$ & N/A & $7 \cdot 5$ & $9 \cdot 1$ \\
\hline $\mathrm{PaCO}_{2}(\mathrm{kPa})$ & N/A & $3 \cdot 1$ & $3 \cdot 4$ \\
\hline \multicolumn{4}{|l|}{ Breathing $60 \%$ oxygen via face mask: } \\
\hline Pulse rate (beats/min) & 80 & 130 & 100 \\
\hline Respiratory rate (breaths/min) & 26 & 28 & 20 \\
\hline $\mathrm{PaO}_{2}(\mathrm{kPa})$ & 11 & $15 \cdot 2$ & $10 \cdot 9$ \\
\hline $\mathrm{PaCO}_{2}(\mathrm{kPa})$ & $4 \cdot 5$ & $4 \cdot 9$ & 3.9 \\
\hline \multicolumn{4}{|c|}{$\begin{array}{l}\text { Breathing } 60 \% \text { oxygen via face mask prior to } \\
\text { the introduction of CPAP: }\end{array}$} \\
\hline Pulse rate (beats/min) & 120 & 130 & 110 \\
\hline Respiratory rate (breaths/min) & 33 & 32 & 40 \\
\hline $\mathrm{PaO}_{2}(\mathrm{kPa})$ & $8 \cdot 8$ & $9 \cdot 7$ & $8 \cdot 8$ \\
\hline $\mathrm{PaCO}_{2}(\mathrm{kPa})$ & $4 \cdot 3$ & $5 \cdot 3$ & $4 \cdot 9$ \\
\hline \multicolumn{4}{|c|}{$\begin{array}{l}\text { Breathing } 60 \% \text { oxygen via face mask with } \\
10 \mathrm{~cm} \mathrm{H}_{2} \mathrm{O} \text { CPAP: }\end{array}$} \\
\hline Pulse rate (beats/min) & 85 & 120 & 100 \\
\hline Respiratory rate (breaths/min) & 24 & 20 & 32 \\
\hline $\mathrm{PaO}_{2}(\mathrm{kPa})$ & $26 \cdot 3$ & $17 \cdot 8$ & $12 \cdot 8$ \\
\hline $\mathrm{PaCO}_{2}(\mathrm{kPa})$ & $5 \cdot 2$ & $5 \cdot 3$ & $5 \cdot 1$ \\
\hline
\end{tabular}

N/A-not available.
4.7 per 1000 adult population cases annually. ${ }^{1}$ Guidelines for the identification and management of the more seriously ill patients have been published which include criteria for admission to intensive care and the institution of ventilatory support. ${ }^{2} \mathrm{We}$ report three cases who fulfilled these criteria and were given ventilatory support with continuous positive airway pressure (CPAP) via a face mask rather than intermittent positive pressure ventilation (IPPV), and comment on the advantages and potential disadvantages of this system.

\section{Patients and results}

Three white male patients aged 17, 22 and 33 years who had previously been well and were current smokers presented with a history and physical findings suggestive of community acquired pneumonia which was confirmed radiographically. As shown in table 1 , cases 2 and 3 exhibited features associated with increased mortality ${ }^{2}$ on admission to hospital. Supportive treatment with supplemental oxygen via a face mask (Ventimask) in a concentration of $60 \%$ and intravenous fluids was started on admission and, following collection of appropriate samples for microbiological and serological analysis, all three were treated with intravenous cefuroxime and erythromycin. Initial improvement in all cases was followed by increasing distress, accompanied by a rising pulse and respiratory rate and significantly worsening hypoxia 4-36 hours after admission.

Ventilatory support was provided with 10 $\mathrm{cm} \mathrm{H}_{2} \mathrm{O}$ of CPAP (Ambu CPAP system) applied via a tightly fitting face mask. The concentration of inspired oxygen was controlled with a Vickers Medical model 135 air/oxygen blender and was initially set at $60 \%$. An immediate clinical improvement occurred in each patient as shown in table 2 . Following 12 and 18 hours of CPAP respectively, cases 1 and 2 went on to make a full recovery. Case 3 developed the adult respiratory distress syndrome and required IPPV for nine days before making a full recovery.

The CPAP face mask was well tolerated by all patients and no patient developed carbon dioxide retention.

Despite the investigations detailed above, the organism responsible was only determined in case 2, Streptococcus pneumoniae being cultured from the sputum.

\section{Discussion}

Continuous positive airway pressure provided effective ventilatory support in our patients suffering from severe community acquired pneumonia, improving both symptoms and hypoxia thereby allowing time for antimicrobial treatment to effect a clinical improvement and for recovery to occur. That this was not sustained in one case was due to the development of a recognised complication of community acquired pneumonia and subsequent deterioration in pulmonary function. 
The mechanisms by which hypoxaemia is produced in severe community acquired pneumonia include anatomical shunting and ventilation/perfusion mismatch. ${ }^{3}$ There is also a reduction in thoracic compliance and subsequent increase in respiratory work leading to fatigue. ${ }^{4}$ Continuous positive airway pressure improves oxygenation by increasing pulmonary pressure throughout the respiratory cycle, thereby increasing lung volume. ${ }^{5}$ This has the effect of decreasing the anatomical shunt and improving ventilation/perfusion matching; as compliance is raised the work of breathing is reduced. The use of CPAP delivered by face mask, if successful, avoids endotracheal intubation and IPPV with its associated risks including cardiovascular depression, barotrauma, and increased susceptibility to nosocomial infection. ${ }^{6-8}$ If, however, CPAP is not effective we emphasise that IPPV should be instituted without delay, and would recommend that CPAP only be administered under close medical supervision where this facility is immediately available.

The greatest potential complication of CPAP is the aspiration of gastric contents, so patients in whom its use is being considered must be orientated, cooperative, and not suffering from nausea or vomiting. ${ }^{9}$

Although CPAP is well recognised and used as an adjunct to treatment in Pneumocystis carinii pneumonia, ${ }^{10}$ this does not appear to be the case for community acquired pneumonia where the potential for rapid resolution and recovery are greater. We suggest that greater consideration is given to this form of ventilatory support in patients with deteriorating pulmonary function meeting the above criteria.

We are grateful to Lieutenant Colonels Winfield and Fabricius for permission to report these cases.

1 Woodhead MA, Macfarlane JT, McCracken JS, Rose DH, Finch RG. Prospective study of the aetiology and outcome of pneumonia in the community. Lance 1987;i:671-4.

2 Harrison BDW, Farr BM, Connolly CK, Macfarlane JT, Selkon JB, Bartlett CLR. The hospital management of community acquired pneumonia. Recommendations of the British Thoracic Society. $f R$ Coll Phys 1987; 21:267-9.

3 Lampron N, Lemaire F, Teisseire B, Harf A, Palot $M$, Matamis D, et al. Mechanical ventilation with $100 \%$ oxygen does not increase intrapulmonary shunt in patients with severe bacterial pneumonia. Am Rev Respir Dis 1985;131:409-13.

4 Mink SN, Light RB, Wood LDH. Effect of pneumococcal lobar pneumonia on canine lung mechanics. $f$ Appl Physiol 1981;50:283-91.

5 Linder KH, Lotz P, Ahnefeld FW. Continuous positive airway pressure effect on functional residual capacity, vital capacity and its subdivisions. Chest 1987;92:66-70.

6 Lutch JS, Murray JF. Continuous positive-pressure ventilation: effects on systemic oxygen transport and tissue oxygenation. Ann Intern Med 1972;76:193-202.

7 Hillman K. Pulmonary barotrauma. Clin Anaesthiol 1985;3:877-98.

8 Craven DE, Kunches LM, Killinsky V, Lichtenberg DA, Make BJ, McCabe WR. Risk factors for pneumonia and fatality in patients receiving continuous mechanical ventilation. Am Rev Respir Dis 1986;133:792-6.

9 Branson RD. PEEP without endotracheal intubation. Respir Care 1988;33:598-610.

10 Miller RF, Semple SJ. Continuous positive airway pressure ventilation for respiratory failure associated with Pneumocystis carinii pneumonia. Respir Med 1991;85 133-8.

\section{Endobronchial nocardial infection}

\author{
Keith D McNeil, David W Johnson, \\ William A Oliver
}

\begin{abstract}
The rare presentation of nocardial infection as an endobronchial "tumour" is reported. Haematogenous dissemination occurred after fibreoptic bronchoscopy and biopsy, a phenomenon not previously described in nocardial infections. This case highlights the difficulties in diagnosing pulmonary nocardial infection and the potential for invasive procedures to disseminate the disease.
\end{abstract}

(Thorax 1993;48:1281-1282)

Pulmonary nocardiosis is uncommon, but this infection is becoming increasingly important with the widespread use of immunosuppressive treatment in transplant recipients and patients with malignancy. ${ }^{1-3}$ The disease is caused by several species of the genus Nocardia which most commonly behave as opportunistic pathogens in the compromised host. ${ }^{1}$ Pulmonary infection is the commonest form of the disease with dissemination from the lungs to other sites occurring in up to $50 \%$ of cases. ${ }^{24}$ Pulmonary nocardiosis presenting as an endobronchial tumour is, however, uncommon with only two previously reported cases. ${ }^{56}$

\section{Case report}

A previously healthy 70 year old male smoker presented with a three month history of nonproductive cough, dyspnoea, anorexia, and weight loss. On admission he was afebrile. Chest auscultation revealed diminished breath sounds throughout the right lung associated with a monophonic wheeze. The remainder of his physical examination was normal. The neutrophil count was elevated at $24 \times 10^{9} /$ litre. The erythrocyte sedimentation rate was $90 \mathrm{~mm}$ in the first hour. A chest radiograph showed a right hilar mass (fig 1) and a computed tomographic scan showed this mass to be encroaching on the lumen of the right upper lobe bronchus (fig 2). At fibreoptic bronchoscopy there was obstructing "tumour" in the right main bronchus. Endobronchial biopsy specimens showed acute and chronic inflammatory changes with no evidence of granuloma formation. There was no evidence of malignancy. 